\title{
Em busca da pessoa transexual "verdadeira": sobre a produção de dignidade e cidadania diferenciais
}

LUiza Ferreira Lima

Universidade de São Paulo, São Paulo, São Paulo, Brasil

DOI 10.11606/issn.2316-9133.v25i25p267-292

resumo Este artigo investiga sistemas de classificação e padrões de subjetividade política subjacentes à lógica argumentativa elaborada por magistrados(as) ao julgarem ações de retificação de nome e "sexo" em documentos de identificação requeridas por pessoas transexuais em Tribunais Estaduais brasileiros. A partir de minha pesquisa de mestrado e da análise de decisões judiciais publicadas entre 2000 e 2014, proponho o questionamento do modelo universalizante de cidadania apresentado pelo Direito e aponto sentidos de sofrimento, merecimento, doença e pessoa, bem como a articulação de marcadores sociais da diferença, tais quais gênero e sexualidade, como elementos que fundam o reconhecimento da titularidade a direitos.

palavras-chave Transexualidade; Tribunais Estaduais; Cidadania; Pessoa; Marcadores sociais da diferença.

In search of the "true" transexual person: about the production of differential dignity and citizenship

abstract This article investigates classification systems and patterns of political subjectivity underlying the argumentative logic elaborated by magistrates when judging pleas for rectification of name and "sex" in legal documents demanded by transexual people in Brazilian State Courts. From my master's research and the analysis of judicial decisions published from 2000 to 2014, I propose the questioning of the universalizing model of citizenship presented by Law and point meanings of suffering, merit, illness and personhood, as well as to the articulation of social markers of difference, such as gender as sexuality, as elements that establish the acknowledgement of entitlement to rights.

keywords Transexuality; State Courts; Citizenship; Personhood; Social 
markers of difference.

\section{Introdução}

A atividade judicial realizada por magistrados(as) ao avaliarem ações de retificação de nome e "sexo"1 em documentos de identificação requeridas por pessoas transexuais é dinâmica, produtora de sentidos. O caráter realizador e transformador do processo decisório abrange o acionamento de regras e princípios que compõem o corpo normativo nacional - ainda que não haja leis específicas sobre a possibilidade de pessoas transexuais retificarem registro civil.

A Lei de Registros Públicos, mobilizada para resolução de demandas de retificação de pessoas cisgêneras, ${ }^{2}$ não vem sendo considerada suficiente pelo Judiciário para análise de casos de pessoas trans por não tratar das implicações de gênero acarretadas nestes (seja em termos de alteração de "sexo" no documento, seja em termos de atribuição de um nome generificado). Ademais, embora, há décadas, projetos de lei $^{3}$ que pretendem regulamentar a questão tenham sido apresentados e tramitem no Congresso, nenhum foi sancionado e entrou em vigor até agora, fazendo com que o reconhecimento da identidade de gênero de pessoas trans em termos de nominação e identificação dependa de regulamentos vagos ou precários.

É o caso dos decretos estaduais no Rio Grande do Sul (49122/2012), Pará (726/2013) e Goiás (8716/2016), por exemplo, que instituem uma carteira de nome social similar a um RG para transexuais e travestis, válida apenas no

\footnotetext{
${ }^{1}$ Sexo, neste texto, é usado com aspas sempre que tratar da categoria presente em documentos de identificação brasileiros. Este é o termo legal que se refere ao que a teoria jurídica chama de "estado da pessoa", como a pessoa foi designada ao nascer - homem ou mulher. Não há, contudo, nenhum detalhamento na legislação ao que esta palavra significaria: identidade de gênero? Genótipo? Anatomia? Problematizo melhor os sentidos que a palavra recebe judicialmente em minha dissertação de mestrado (LIMA, 2015).

2 "Cisgênero", segundo A. Finn Enke (2013), tem origem latina, com prefixo - "cis" - que designa coisas que se mantêm, sem mudanças de propriedade. Quanto à identidade de gênero, "cisgênero" denotaria a condição de pessoas que mantêm a identidade de gênero a elas atribuída ao nascer. O termo sinalizaria estabilidade e pertencimento a padrões de gênero definidos, ao passo que "trans", seu aparente oposto, sinalizaria mudança, trânsito ou transformação desses padrões. Seu uso, como sugere Enke, está em constante reelaboração e disputa no cenário de estudos trans.

${ }^{3} \mathrm{O}$ primeiro projeto de lei que visou regulamentar a mudança de nome de pessoas transexuais foi o 70/1995, e apresentou como condição para tanto a realização de cirurgia de transgenitalização. Desde então, segundo estudo de Rosa Oliveira (2013), outros projetos com propostas distintas foram levados ao Legislativo (3727/1997, 5872/2005, 6655/2006, 2976/2008 e 1281/2011); o último foi o PL 5002/2013 ("PL João Nery"), de autoria de Jean Wyllys e Érika Kokay, que, similarmente à Lei de Identidade de Gênero argentina, reivindica a retificação de registro de pessoas trans em âmbito administrativo mediante o comparecimento de testemunhas que atestem a identidade de gênero da requerente, sem necessidade de laudos médicos e psicológicos.
} 
território estadual. É também o caso de portarias, resoluções e decretos nas instâncias municipal, estadual e federal que implementam de modos distintos o uso do nome social em órgãos da administração pública, instituições de ensino etc. ${ }^{4}$ A despeito da inegável importância dessas conquistas, trata-se de documentos frágeis (podem ser revogados com relativa facilidade), incongruentes entre si (cada um propõe procedimentos específicos, como uso do nome social em documentos públicos e/ou oficiais ou apenas em circulação interna, acompanhado do nome de registro ou não) e limitados (são válidos para instituições específicas, como escolas públicas, hospitais públicos etc.).

Esses vácuo e precariedade legislativos não impedem magistrados(as) de instrumentalizar documentos legais em diferentes patamares da hierarquia legislativa para sustento de suas motivações. O que mais chama a atenção pela recorrência é a dignidade da pessoa humana, princípio constitucional previsto como um dos fundamentos da República enquanto Estado de Direito. A sua contínua menção pode implicar que se digam as mesmas palavras, mas não que elas signifiquem a mesma coisa; seu sentido se estabiliza e se transforma conforme as circunstâncias históricas, sociais e discursivas de sua citação. E é isso que torna a palavra da lei antropologicamente interessante.

Neste artigo, com base no recorte adotado em minha dissertação de mestrado (LIMA, 2015) - a saber, 84 decisões judiciais publicadas por Tribunais Estaduais brasileiros, de 2000 a 2014 - e nas análises empreendidas, pretendo sintetizar os fatores cuja presença é elaborada como fundamental por magistrados(as) para que a transexualidade afirmada pelo(a) requerente seja reconhecida, de que modo isso se relaciona com a mobilização do princípio da dignidade da pessoa humana e os mecanismos de significação das palavras "pessoa" e "cidadania" a partir da articulação de marcadores sociais da diferença como gênero e sexualidade, em oposição ao modelo universalizante afirmado pelo direito.

\section{Aproximações entre direito e medicina na produção do(a) "verdadeiro/a transexual"}

Nas decisões analisadas, notei que magistrados(as) elaboravam um modelo normativo de pessoa transexual, formado por expectativas de comportamento e critérios a serem observados pelos(as) requerentes para que sua demanda tivesse uma resposta positiva.

Embora discordâncias entre julgadores(as) sejam frequentes, a lógica discur-

\footnotetext{
${ }^{4}$ Pará, Piauí, São Paulo, Pernambuco, Rio de Janeiro e Mato Grosso do Sul, por exemplo, têm decretos referentes ao uso de nome social em órgãos da administração pública estadual direta e indireta. Goiás, Pará, Santa Catarina e Tocantins têm resoluções e portarias que tratam do nome social em unidades de ensino estaduais. Antes do seu afastamento do cargo, Dilma Rousseff sancionou o decreto $\mathrm{n}^{\mathrm{o}} 8727 / 2016$, que institui o uso de nome social na administração pública federal direta, autárquica e fundacional.
} 
siva varie entre os diferentes Tribunais Estaduais e haja notáveis contradições na construção argumentativa de magistrados, pode-se delimitar características aventadas pelas decisões judiciais como constitutivas do que se apreende como "pessoa transexual verdadeira" e modelo de transexualidade considerado generalizado, único, autêntico e legítimo e, portanto, critério definidor de reconhecimento do acesso a direitos. Aqui pretendo apenas sublinhá-las.

A primeira é o diagnóstico positivo: a transexualidade ainda é considerada um transtorno mental e comportamental (na modalidade "transtorno de identidade de gênero") pela Organização Mundial de Saúde. No Brasil, o primeiro regulamento voltado ao tema da transexualidade foi a Resolução do Conselho Federal de Medicina no $1482 / 1997^{5}$ (revogada pela 1652/2002, e esta pela $1955 / 2010$, atualmente em vigor), que a qualifica como desvio psicológico de identidade, estabelece critérios para atribuição do diagnóstico e regulariza a realização de intervenções corporais que compõem o "processo transexualizador", definido como prática terapêutica. Isso tem implicações nos tribunais.

Sem a atribuição, por agentes da medicina e dos saberes psi, da condição de doente à pessoa requerente, de acordo com os parâmetros estabelecidos pela $10^{\mathrm{a}}$ versão da Classificação Internacional de Doenças da OMS e pelas resoluções do Conselho Federal de Medicina, o caso é negado com massiva frequência. Embora haja Tribunais que venham relativizando a importância de documentos comprobatórios produzidos por autoridades dessas áreas, a linguagem utilizada para tratar do tema ainda é carregada de elementos patologizantes. Vejamos o voto do relator em Ação de Apelação no 70011691185, julgada em 15 de setembro de 2005 no Tribunal de Justiça do Rio Grande do Sul:

Inicialmente, julgo pertinentes algumas considerações conceituais sobre transexualidade (estado apresentado por J. A. P., e devidamente diagnosticado - F64.0 CID-10):

[...] "Para se entender o transexualismo, primeiramente é importante se compreender o que é identidade de gênero e como se forma. A identidade de gênero refere-se à masculinidade e à feminilidade, ou melhor, à convicção que cada um tem sobre si de ser masculi-

\footnotetext{
${ }^{5}$ Em 1997, o Conselho Federal de Medicina publicou a Resolução 1482, que pela primeira vez estabelecia os critérios para realização de intervenções corporais de transformação de gênero em pessoas transexuais como práticas terapêuticas, rompendo com o posicionamento institucional de que qualquer procedimento médico realizado deveria ser qualificado como mutilação e portanto lesão corporal, prática penalmente reprovável. Contudo, apenas com a Portaria 1707/2008 do Ministério da Saúde (revogada pela 2803/2013, agora em vigor), que institui o "processo transexualizador" no Sistema Único de Saúde, há uma implementação de procedimentos gratuitos de readequação de gênero a partir do paradigma de atenção integral (ALMEIDA; MURTA, 2013, p. 390-391).
} 
no ou feminino. Isso se forma muito precocemente, desde o estágio intrauterino, e decorre: da soma de causas genéticas e hormonais (vão determinar os caracteres físicos do bebê, se vai nascer com características de menino ou menina); da atitude dos pais ao aceitar ou não o sexo do bebê, a forma como esse bebê vai ser manuseado e tratado (a menininha ou o garotão); da interpretação do bebê a respeito dessas atitudes paternas; da formação do ego corporal (o bebê vai formando uma ideia a respeito de si a partir de sensações que surgem com a manipulação de seu corpo). [...]

Em tal hipótese, o transexual sente "um sofrimento psíquico por acreditar que houve um erro na determinação do sexo anatômico. $E$ devido a esse sentimento que muitos buscam a cirurgia para mudança de sexo, na tentativa de correção do erro que sentem haver the acontecido e assim aliviar o sofrimento".

Quanto ao diagnóstico médico, psiquiatras ou psicólogos o fazem "através de várias conversas com o paciente, para determinar corretamente os sentimentos dele", sendo que um "tratamento psicológico se faz necessário para entender a alteração apresentada e apenas em alguns casos específicos será indicado a cirurgia de alteração do sexo, a qual só se faz após cuidadosa avaliação psicológica e física da pessoa". (itálicos e negritos do autor)

Os termos acionados são próprios dos saberes biomédicos: fala-se na etiologia da "doença", em sintomas como o sofrimento psíquico e na importância do diagnóstico. Mas essa lógica que torna a pessoa transexual inteligível é muito mais complexa do que a simples afirmação de que uma pessoa é doente: há elementos apresentados como requisitos para a atribuição do diagnóstico que, ao instituírem o que saberes biomédicos definem como "transexualismo", também definiriam a "identidade transexual". Espera-se aversão ao aparelho genital tal como é conformado antes da cirurgia de transgenitalização e incapacidade de sentir prazer com ele, uma performance de gênero (usualmente comprovada por fotografias juntadas aos autos do processo), construída a partir de vestimentas, técnicas e intervenções corporais, sociabilidades e indicativos de comporta- 
mento, ${ }^{6}$ que corresponda a modelos tradicionais e hegemônicos de feminilidade e masculinidade, e uma narrativa biográfica ${ }^{7}$ que ateste a permanente inadequação ao gênero designado ao nascer e a constante e progressiva construção da identidade de gênero reivindicada pela pessoa.

É também frequente que se exija que essa narrativa seja qualificada pelo sofrimento, produzido por uma sensação de desajuste fundamental entre corpo e mente, pelo anseio por reconhecimento social quanto ao pertencimento a outro "sexo" e pelos conflitos sociais gerados por esse descompasso entre qualificação oficial do sujeito e a forma como reivindica ser identificado; que o/a requerente esteja passando pelo chamado "processo transexualizador", ou que este já tenha se encerrado com a realização da cirurgia de transgenitalização; e que a pessoa sinta desejo e se relacione erótico-afetivamente com pessoas de "sexo" oposto ao qual reivindica pertencer.

Não apenas estamos diante de discursos que estabelecem prescrições de gênero e regimes de moralidade a partir de uma matriz de inteligibilidade heteronormativa; ${ }^{8}$ mas também de um processo que é realizado por meio da criação de um modelo jurídico de pessoa transexual verdadeira, um processo que se apropria de, e se apoia em, linguagem e normas médicas e se torna paradigma

\footnotetext{
${ }^{6}$ Nas fotografias que encontrei nos autos de processo aos quais tive acesso, era comum que mulheres transexuais fossem retratadas com amigas ou familiares mulheres em momentos de descontração - quando não com namorados, noivos, companheiros homens. Os homens transexuais, por sua vez, apresentavam registros de práticas de esportes e confraternização com amigos homens. As imagens de mulheres se dão em meio a bichos de pelúcia, animais de estimação, ou em poses sensuais em seus quartos, na praia etc. As de homens mostram brincadeiras agressivas entre amigos e uma apresentação de si mais casual. É possível notar modelos de masculinidade e feminilidade sendo acionados por meio da representação imagética. Para uma análise mais detida, ver Flávia Teixeira (2013) e Lucas Freire (2015).

${ }^{7}$ Como afirma Cynthia Sarti (2009), mostramos a estabilidade da regra pelo acionamento de sua exceção: usualmente requerentes apresentam narrativas biográficas que demonstram permanência do desconforto causado pelo descompasso entre o gênero designado ao nascerem e a identidade de gênero que reivindicam, mas isso não se deu na Ação de Apelação no 048090177907 , processada no Tribunal de Justiça do Espírito Santo e julgada em 25 de maio de 2010. O relator mencionou, entre outros motivos para negar o pedido: "de mais a mais, sequer mostrou ter crescido e se desenvolvido como se mulher fosse, apesar de deixar clara sua orientação sexual". ${ }^{8}$ Por "matriz de inteligibilidade" entendo a "matriz cultural por intermédio da qual a identidade de gênero se torna inteligível [e que] exige que certos tipos de identidade não possam existir" ou sejam considerados "falhas de desenvolvimento" (BUTLER, 2013[1990], p. 39). O principal fator que tornaria o gênero inteligível seria a instituição e manutenção de relações de coerência e continuidade entre sexo, gênero, prática sexual e desejo. A sua quebra produziria confusão, impossibilidade, ilegibilidade. Por heteronormatividade, entendo o posicionamento da heterossexualidade como propriedade inata a seres humanos e fundamento da sociedade (WARNER, 1991). Subjacente a essa lógica aparentemente constatativa, desvelar-se-iam mecanismos de normatização e gestão da sexualidade e desejo, criando modelos de indivíduos aceitáveis, coerentes (que seguiriam o modelo), e outros anormais e desviantes (que não se enquadrariam nele). Mais do que forma de classificação, a heteronormatividade sugere mecanismos de significação e legitimação de sujeitos, implicando acesso a prerrogativas sociais - como a visibilidade não estigmatizada.
} 
de análise de quaisquer requerentes que demandem a mudança. É a partir desse modelo, da delimitação dos elementos que o caracterizam e das expectativas de comportamento aceitável ou não que o Judiciário atribui inteligibilidade a pessoas que empreendem transformações de gênero e constrói estabilidade no ato de julgar.

Valho-me aqui da categoria analítica elaborada por Berenice Bento (2006) para designar o produto da dinâmica de generalização e normatização da experiência da transexualidade pelos saberes e instituições biomédicas e psi. A elaboração de características tomadas como necessariamente compartilhadas por todas as pessoas transexuais seria uma forma de estas instituições atribuírem lugar e sentido a formas de ser que transgridem normas de gênero e instaurarem parâmetros de atendimento; contudo, os efeitos produzidos são o de estabelecimento "como verdadeira uma única possibilidade de resolução para os conflitos entre corpo, subjetividade e sexualidade" (BENTO, 2006, p. 151) e a deslegitimação de outras.

Mario Carvalho (2011) também se refere à definição da transexualidade "verdadeira" em termos médicos como uma forma de purificação que enfrenta a exclusão simbólica de transexuais e os inclui no espectro de inteligibilidade do humano, viabilizando negociações como o acesso a direitos e se tornando meio de luta por cidadania. Todavia, seu resultado, para além da estigmatização da doença, é a produção de subjetividades e performances de gênero medicamente desejáveis e disciplinadas, definidas e rotuladas pelo diagnóstico, que se adequariam às normas de gênero que organizam a ordem social. Uma pessoa transexual "verdadeira" é a que se aproximaria ao máximo do que se espera que um homem ou mulher "verdadeiros" devam ser.

Nesse espaço de articulação entre medicalização e direitos, Miriam Ventura e Fermin Schramm (2009) examinam de que modo o protocolo diagnóstico e terapêutico produzido por instituições médicas em torno da transexualidade produz prescrições que estabelecem modos corretos de se vivenciar a transexualidade e influenciam a prática judicial. $\mathrm{O}$ cerne argumentativo dos tribunais se organizaria não em termos de exercício pleno de liberdade e cidadania para todos(as), mas de enquadramento ou não de requerentes às normas médicas diagnósticas e à realização de procedimentos de "correção de desvio". Ajustar-se ao modelo de "pessoa transexual verdadeira" levaria à titularidade a direitos particulares atribuídos a esse tipo particular de sujeitos.

Isso se dá, de acordo com os(as) autores(as), como forma de operadores(as) do Direito atribuírem sentido e legitimidade à reivindicação de identidades de gênero distintas das atribuídas "biologicamente"; ocorre que isso se dá pela produção de um único modelo normativo autêntico e justificável, fundado na patologização da experiência e na exclusão simbólica de todas as demais formas de transição de gênero que não se encaixem nesse modelo. 
Mas aqui não se trata de mera transposição de um modo de operação médico ao âmbito judicial; o estabelecimento de sistemas de classificação de sujeitos e de atribuição diferencial de expectativas de comportamento aceitáveis e inaceitáveis a diferentes grupos não organiza apenas nexos de doença e saúde, mas também faz parte da gestão de reconhecimento de titularidade de direitos, bem como de reprovação e sanção de condutas no meio judiciário.

\section{Aproximações entre "pessoa transexual verdadeira" e “homem razoável"}

Max Gluckman (1955) deteve-se na dinâmica de produção de figura semelhante à da "pessoa transexual verdadeira" ao investigar a prática judicial barotse, no centro-sul da África. O autor afirma que, assim como no Direito britânico, o que denomina "homem razoável" tem protagonismo no sistema barotse porque é o meio pelo qual normas abstratas se tornam aplicáveis a diferentes circunstâncias concretas da vida. Não se trata de um modelo ideal de indivíduo produzido imparcial e objetivamente; é elaborado em suas formas diferenciais a partir de valores, status, moralidades e representações sociais definidos por articulações entre gênero, sexualidade, geração e outros marcadores sociais da diferença. Assim, o "homem razoável" nunca é apresentado como uma figura de sujeito universal - nos julgamentos que acompanhou, fala-se em "esposa sensata", "pai decente", "bom chefe" etc.

Esses modelos derivados de "pessoa razoável" são formados com base em costumes e padrões específicos a posições sociais distintas, diferenciando-se trajetórias, atitudes e emoções esperadas, exigidas e vedadas a pessoas diferentes que ocupam lugares sociais diferentes, e se distanciando de uma simples aplicação de legislação ou jurisprudência generalizável a qualquer cidadão(ã). Gluckman assevera que a determinadas figuras sociais é aceitável esperar o não cumprimento de certas normas e seguimento de outras, criando-se zonas de permissividade e controle conforme o papel que se exerce.

Esses modelos não são cristalizados. Gluckman reitera que é justamente a sua porosidade aos sentidos e valores em circulação social que permite a adequação de normas jurídicas fixas às transformações sociais: o que se entende por esposos(as), parentes, líderes razoáveis sofre transformações com o tempo, e julgadores(as) constantemente reelaboram seus modelos de modo a acompanhar essas mudanças e absorver novos preconceitos, costumes, interesses individuais e coletivos com uma velocidade que o Legislativo não consegue alcançar (GLUCKMAN, 1963, p. 192).

Nas decisões que analisei, a prática discursiva de caracterização da "identidade transexual" e sua mobilização como critério normativo cuja observância é necessária ao reconhecimento de direitos me aproxima das categorias de Bento e 
Gluckman: de fato, magistrados(as) se apropriam de - e ressignificam - códigos e linguagem biomédicos a partir de pressupostos heteronormativos de masculinidade e feminilidade e regimes de moralidade; mas o fazem, como constatou Gluckman, em um processo de concretização de normas abstratas e gerais, de instituição de certa estabilidade a demandas que não têm uma resposta única e definida pelo Legislativo, e de diferenciação de sujeitos de direitos - a determinação de quem são em um sistema classificatório e do modo como nele se encaixam define o que a eles será permitido, vetado e imposto.

Como exemplo dessa aproximação possível, volto-me novamente às narrativas de sofrimento que, como esperam os/as desembargadores(as), fazem parte da reconstituição biográfica dos(as) requerentes e/ou sejam atestadas pelos laudos médicos e psicológicos. Esse sofrimento aguardado e descrito como inexorável à vida da "pessoa transexual verdadeira" é apresentado a partir de duas origens explicativas. Uma é de ordem biológica: diversos/as julgadores(as) assumem que o "transexualismo" enquanto doença provoca o descompasso entre o gênero expresso pela mente e o expresso pelo corpo, e essa incoerência geraria dor profunda. Em voto na Ação de Apelação no 5751/2012, processada no Tribunal de Justiça de Sergipe e julgada em 30 de outubro de 2012, o relator explica:

Pois bem, o transexualismo, definido como patologia pela Classificação Internacional de Doenças, consiste em uma anomalia da identidade sexual, em que o indivíduo se identifica psíquica e socialmente com o sexo oposto ao que lhe fora determinado pelo registro civil. $\mathbf{O}$ transexual não aceita seu sexo biológico, buscando na cirurgia de redesignação sexual o fim de todo aquele sofrimento causado pela incoincidência entre sua identidade sexual física e psíquica. Essa angústia não se resume no fato de a sociedade o encarar como indivíduo do outro sexo, mas se agrava quando o próprio transexual não consegue conciliar seu corpo à sua mente: ele se olha no espelho e vê algo que repudia, que reprova. (grifo nosso)

Notemos, para além do indicativo de composição de uma figura generalizada de pessoa transexual (“O transexual não aceita..."), a assertiva de que o sofrimento é causado pela patologia e a discrepância que provoca. O conflito é posicionado não no meio social e nas normas e prescrições de gênero que nele se desenvolvem e regulam condutas e subjetividades - mas no indivíduo, tendo a doença como fonte geradora. Despolitiza-se e se medicaliza esse regime de emoções.

Há desembargadores(as) que reconhecem a produção de sofrimento a partir de interações sociais vivenciadas por pessoas transexuais; essa é a segunda origem explicativa presente em decisões. Uma das possibilidades de produção 
desse sentimento se dá a partir da diferença entre a apresentação de si e os dados registrados em documentos de identificação: situações triviais como viagens de avião, exercício do direito de voto ou candidatura para emprego - casos em que documentos de identificação precisam ser mostrados - provocam desconforto ao tornar pública a discordância entre a identidade de gênero reivindicada pela pessoa pleiteante e a forma como é registrada pelo Estado. Na Ação de Apelação no 2011.034720-1, processada no Tribunal de Justiça de Santa Catarina e julgada em 23/08/2011, o relator argumenta:

a parte autora é alvo constante de constrangimento e de exposição ao ridículo, porque o nome que porta é de uso predominantemente do sexo oposto àquele que ostenta, resultando em evidente desconforto e sofrimento psicológico, pois desnatura a sua personalidade. $\mathrm{O}$ constrangimento mencionado se repete cada vez que o nome da parte autora é pronunciado, o que não corresponde à expectativa dos atributos que associamos ao prenome, parecendo-nos que isto causa desassossego que deve ser evitado.

Malgrado se afirme que a angústia pode ter origem social, ela é apresentada como possível apenas a partir do descompasso entre corpo e mente, ou entre identidade de gênero e apresentação de si e documentos de identificação. Nos dois casos, o "transexualismo" é delineado como doença causadora do sintoma, não as normas sociais de gênero apreendidas como naturais, fixas e universais que levam à ininteligibilidade, não reconhecimento ou estigmatização dos(as) que a elas não se adequam (BUTLER, 2009) e, assim, acarretam exclusão social, prejudicam relações de afeto, e os/as expõem à violência (ARÁN; MURTA, 2009, p. 21-22).

Não se trata de alegações aleatórias de experiência de sofrimento que convencem magistrados sentimentais e suscetíveis; as decisões indicam que há expectativas de um sofrimento qualificado, individualizado, patológico, legítimo -

e necessário. É o que vitimiza a pessoa transexual e torna a concessão de direitos justificável. $\mathrm{O}$ ato discursivo de precisá-lo como característica inerente à pessoa transexual produz, simultaneamente, a exigência de sua verificação e suspeita diante de sua ausência. Ele traz consigo o caráter homogeneizador e normativo que se impõe às subjetividades trans, como afirma Bento, e à expectativa de seu cumprimento para acesso a direitos, sustentada em valores e sentidos sociais do que se entende como "transexual razoável" - para usarmos os termos e a lógica de Gluckman.

\section{Os sentidos de pessoa que organizam discursos}


Sofrer e fazer sofrer pelos motivos e de formas esperados tem tanta preponderância nas decisões quanto seus pressupostos narrativos: um é o desejo de eliminação de qualquer dualidade de gênero patológica que habite o/a requerente; o outro é a imperatividade dessa eliminação para que se integre à sociedade. Quanto ao primeiro, julgadores(as) elaboram uma lógica valorativa em torno da transexualidade que necessariamente representa a dualidade de gênero como negativa. Isso se dá porque "sexo" é apreendido em termos de masculino e feminino, como categorias opostas e discretas, excludentes e exclusivas com fundamento na biologia, estável e universal. A "mistura”, a coabitação entre masculino e feminino, não é vista como natural, saudável ou aceitável. Qualquer indicação de sua existência é justificada a partir de uma linguagem de doença que precisa ser tratada. Assim, uma pessoa que se identifica com gênero distinto do atribuído a ela ao nascer é comumente lida nos tribunais como descreve o relator em Ação de Apelação no 350.969-5 julgada em 7 de abril de 2007 no Tribunal de Justiça do Paraná:

Então, o transexual é aquele que [...] se intensifica o seu desejo e irresignação, com sua natureza biológica, [...] considerada uma doença rara da psique humana e não um mero capricho ou vaidade, já que tais indivíduos possuem um "enxergar" de si mesmos, no espelho, de forma equivocada que, ao longo dos anos e maturidade pessoal, acentua-se a ponto de possuírem uma certeza inabalável de que "nasceram no corpo errado".

Essa valoração - de que a pessoa "se enxerga" diferente do que "é" e que isso é uma doença - também se fundamenta no paradigma explicativo que, de acordo com Judith Butler (2013[1990]), produz identidades sexuadas possíveis a partir do estabelecimento de uma ordem compulsória, linear e coerente entre sexo, gênero, prática sexual e desejo: supõe-se que o gênero seria a manifestação cultural necessária do sexo produzido pela natureza, pré-discursivo, e que essa relação entre ambos levaria ao desejo por uma pessoa do "sexo" oposto e complementar, expressa por meio de práticas sexuais.

Seguindo Butler, esses dois pressupostos não correspondem a uma base factual, fundada em uma realidade objetivamente aferível que orienta as práticas de magistrados(as); trata-se de elementos que compõem uma prática reguladora de identidades, criadora de ideais normativos caracterizados pela unicidade, coerência e permanência, em oposição a formas de existência que não podem existir ou devem ser corrigidas. Em meu campo de pesquisa, sofrer com a dualidade e reivindicar sua resolução é condição para o pertencimento à categoria de "pessoa transexual verdadeira", "razoável” para o seu reconhecimento enquanto pessoa possível, legítima, e para a autorização de seu ingresso no rol de cida- 
dãos(ãs). Contudo, antes da produção normativa da transexualidade e das condições para que a suas formas de subjetividade se atribua o caráter de "verdade" ou "razoabilidade", esse debate tem como pressuposto o sentido de "pessoa" que subjaz as práticas judiciais.

Para pensar "pessoa" enquanto categoria moral e normativa, parto de sua problematização e deslocamento do âmbito do inato e do natural feitos por Marcel Mauss (2003[1938]): o sociólogo, a partir de estudo comparativo, demonstra como, ao longo da história e em diversas sociedades, o conceito se transforma e assume configurações distintas com base em estruturas sociais, costumes e mentalidades específicos.

A pessoa, enquanto valor metafísico e moral, substância racional indivisível - donde "indivíduo" -, se delineia a partir do desenvolvimento do cristianismo e da equiparação da unidade das três manifestações representadas pela Trindade, bem como da unidade das duas naturezas de Cristo à do ser humano em corpo e alma. Assim, "é a partir da noção de uno que a noção de pessoa é criada [...] a propósito das pessoas divinas, mas simultaneamente a propósito da pessoa humana" (MAUSS, 2003 [1938], p. 393). Com o Renascimento, a categoria seria definida como fundamento da consciência e da razão.

Seguindo Mauss, Louis Dumont (1985) também se dedica à história de representações e valores ocidentais que levaram à vigência do individualismo enquanto valor fundamental das sociedades modernas. Assevera o autor que, aos poucos, em termos de preponderância ideológica, a noção de indivíduo enquanto ser moral, independente, autônomo se sedimenta, à medida que o protestantismo institui o comprometimento deste nas coisas do mundo (em oposição ao ascetismo do início da religião cristã), influencia o Iluminismo e orienta sutilmente os pilares do ordenamento jurídico moderno ocidental, como a Declaração dos Direitos do Homem e do Cidadão adotada em 1789 - evento que, segundo Dumont, demarca o "triunfo do Indivíduo" (1985, p. 109). Trata-se de um conjunto de representações que atribuem importância valorativa ao indivíduo em detrimento das relações sociais às quais está vinculado e do meio social no qual se encontra, destituindo-os de influência na formação dessa figura de sujeito.

Mais recentemente, pesquisas nas áreas de gênero e sexualidade têm incorporado esses estudos para analisar mecanismos de produção de sentidos de identidade e pessoa em funcionamento a partir da forma como esses marcadores sociais da diferença e outros como raça, classe etc. se articulam e são articulados em contextos locais, mas ocultados em narrativas de categorização identitária. Larissa Pelúcio demonstra como a categoria pode ser relacionada à teoria foucaultiana de constituição de sujeitos a partir da "emergência dos saberes especializados e produzidos por meio de práticas discursivas, objetivadas em técnicas e prescrições institucionalizadas, permeadas por relações de poder” (2007, p. 275). Assevera que a instituição de que há uma verdade definidora de sujeitos e sa- 
beres qualificados para acessá-la observa padrões de gênero e sexualidade que definem técnicas e intervenções corporais de modo que qualquer ambivalência seja eliminada, e subjetividades, controladas.

Assim como a pesquisadora afirma que a construção da pessoa travesti se dá a partir de práticas e comportamentos produzidos por discursos situados em relações de poder e conformes a padrões de gênero e sexualidade que privilegiam coerência e refreiam ambiguidades, o mesmo ocorre em meu campo no que toca à pessoa transexual: ${ }^{9}$ os saberes biomédicos são operacionalizados como referência para dar sentido, estabilizar a experiência de ser transexual perante o Judiciário e estabelecer um lugar de verdade coerente e permanente em quem requer a retificação. Para alguns(as) magistrados(as), a verdade do "sexo" está na psique; para outros(as), está na fisiologia, nos genes, nos genitais. Em comum, suas decisões têm apoio na gramática médica:

tendo o dr. Marcio Litleton assegurado que X possui corpo e mente masculinos. Adverte, ainda, que a ausência da genitália masculina não altera sua identidade de gênero. In verbis: "Não se pode transformar um homem em mulher apenas amputando-lhe o pênis. Um paciente que tem seu pênis amputado por alguma doença ou acidente não vira uma mulher. Um homem que nasce com malformação do pênis, micropênis ou a ausência de pênis não se converte em uma mulher. Da mesma forma, o transexual masculino não necessita de um pênis para ser homem [...]. O que o paciente precisa para ser homem é uma mente normal masculina, aceitação social como homem pelos seus pares, tratamento específico para a disforia de gênero e do reconhecimento legal". (TJRJ, Processo $\mathrm{n}^{\mathrm{o}}$ 0005650-64.2012.8.19.0208 DJ: 25/02/2014, grifo da autora)

Outrossim, levando em consideração que o registro de nascimento deve conter a realidade, não considero possível a retificação do sexo no registro civil. Isso porque, apesar da intervenção cirúrgica e da alteração de nome, o autor ainda

\footnotetext{
${ }^{9} \mathrm{O}$ reconhecimento judicial de pessoas transexuais enquanto Pessoas se dá, concomitantemente, através da alocação de travestis e outras experiências de transformação de gênero em zonas de ilegitimidade, imoralidade e desvio - reproduzindo os fundamentos que subjaziam a produção das propriedades e fronteiras entre normalidade e monstruosidade. Dou especial atenção a isso em minha dissertação de mestrado (LIMA, 2015). A ambiguidade de gênero e sexualidade ainda é temida, principalmente em instituições médicas e jurídicas que funcionam a partir de um sistema classificatório de identidades, corpos e comportamentos e a ele atribuem assimetrias de valor. Para uma análise mais detida do desenvolvimento histórico e contrastivo das categorias “travesti” e "transexual”, ver Jorge Leite Jr. (2011).
} 
é, geneticamente, do sexo masculino, o que pôde ser constatado através do exame acostado às $\mathrm{f}$. 60 , onde se constatou a presença de cromossomos XY, pertinentes exclusivamente ao sexo masculino. (TJMG, Processo no ${ }^{-1.0543 .04 .910511-~}$ 6/001 DJ: 23/02/2006)

A linguagem, as intervenções e as regulamentações da medicina são o meio adotado por julgadores(as) para dar sentido às experiências e às transformações pelas quais pessoas transexuais passam, mantendo o paradigma de pessoa como referência, bem como preservando o modelo sexo-gênero-desejo construído como um dado da natureza. Ambos se articulam em uma matriz de inteligibilidade que organiza a compreensão da transexualidade pelos códigos biomédicos: reconhece-se a pessoa transexual enquanto Pessoa, encontrando um lugar para ela na lógica de designação de indivíduos como coerentes, indivisíveis, estáveis, e também se preserva a heteronormatividade e o sentido de "sexo" como dois polos opostos discretos imiscíveis, exclusivos, excludentes, atemporais.

\section{De pessoa à vítima, de vítima à cidadã}

$\mathrm{O}$ reconhecimento de requerentes como pessoas faz parte do processo de reconhecimento de cidadania. Atestar que se está diante de uma "pessoa transexual verdadeira" é condição necessária para, usualmente, afirmar sua titularidade a direitos. A passagem de uma ponta a outra - da pessoa e, porque pessoa, à cidadã - se dá a partir de dois fatores: a mobilização do princípio da dignidade da pessoa humana e a averiguação do sofrimento que qualificaria a pessoa transexual como vítima.

O princípio da dignidade da pessoa humana é uma das normas mais versáteis do ordenamento jurídico: ela pode ser acionada em diversos contextos distintos em virtude da vagueza de seu texto. Em meu recorte, quando magistrados/as pretendem autorizar a retificação, a presença do princípio em seus argumentos é quase unânime. Na Ação de Apelação no 0368330-41.2012.8.05.0001, tramitada no Tribunal de Justiça da Bahia e julgada em 22 de outubro de 2013, a relatora afirma:

Conquanto é consabido que o direito ao nome e à dignidade da pessoa humana, consagrada como direito fundamental da ordem jurídica constitucional, distingue a pessoa na sua vida em sociedade, passando a significar a marca distintiva do indivíduo, sua indivisibilidade. $O$ direito à personalidade, por sua vez, diz respeito à essência do indivíduo, que deve ser respeitada em qualquer grau de ju- 
risdição e em qualquer situação, levando-se em conta que o transexual, antes de tudo, é cidadão. Conforme disposto no art. 5ำ da Lei de Introdução ao Código Civil, deve o juiz, ao aplicar a lei ao caso concreto, atender e preservar o bem comum, delimitando não só a sociedade como um todo, mas o próprio indivíduo em si, sob pena de violar o princípio da dignidade da pessoa humana, elencado na Constituição da República Federativa do Brasil/1988. (grifo nosso)

Nota-se a pressuposição de indivisibilidade e a presença de certa essência enquanto elementos da pessoa e objeto de proteção. A reiteração de que "o transexual, antes de tudo, é cidadão” também é eloquente e evidencia a importância do modelo de "pessoa transexual verdadeira": não se diz "a requerente" ou sequer "o indivíduo"; diz-se "o transexual". Mas o melhor exemplo de preeminência do princípio enquanto fundamento de acesso a direitos é a Ação de Apelação n⿳o 1.0024.05.778220-3/001, processada no Tribunal de Justiça de Minas Gerais e julgada em 6 de março de 2009. Afirma o desembargador:

A Constituição Federal consagra em todo nosso ordenamento jurídico a proteção aos direitos fundamentais, buscando evitar transtornos decorrentes do direito positivista. [...] Estes direitos estão todos calcados no princípio da dignidade da pessoa humana, dito elemento estruturante do Estado Democrático de Direito, e segundo o qual todo ser humano tem direito a ser respeitado como ser individual. [...]

A dignidade da pessoa humana, atributo fundamental do próprio Estado Democrático de Direito, consagra, de igual forma, e inclui direitos da personalidade que devem ser observados por todos. Os direitos da personalidade decorrem do reconhecimento da dignidade; a personalidade é o atributo genérico reconhecido a alguém para que seja sujeito de direitos e deveres; é a aptidão para titularizar a relação jurídica, tornando-se portador de todos os atributos decorrentes dos direitos da personalidade, dentre eles o direito ao nome. A personalidade tem início com o nascimento com vida e só termina com a morte, sendo intransmissível e irrenunciável. Além disso, a personalidade confere ao ser humano os chamados "direitos da personalidade", que estão vinculados ao reconhecimento 
dos valores inerentes à pessoa humana, imprescindíveis ao desenvolvimento de suas potencialidades físicas, psíquicas e morais, tais como a vida, a incolumidade física e psíquica, o próprio corpo, o nome, entre outras. (grifo nosso)

Mas esse princípio não é apenas afirmado enquanto parâmetro de avaliação e fundamento de direitos básicos, como o direito à personalidade; ele é relacionado especialmente ao sofrimento acarretado pela "doença". Como ilustração, cito a decisão referente à Ação de Apelação no 2012.0001.008400-3, processada no Tribunal de Justiça do Piauí e julgada em 4 de dezembro de 2013. O que chama a atenção aqui é a centralidade dada pelo relator às normas e regras jurídicas: o processo argumentativo se vale muito pouco de saberes biomédicos ou de qualquer esforço de categorização e classificação. Seu voto se limita a explorar jurisprudência, leis e princípios constitucionais, articulando-os em uma economia moral e de afetos:

A manutenção em registro de nascimento e em seus documentos de identificação da indicação de prenome que não corresponde ao modo pelo qual a parte recorrente aparece em suas relações com a sociedade, equivale a deixá-la em situação de incertezas, conflitos, retração, angústia, o que causa abalos e embaraços múltiplos. É negar-lhe o direito de exercer sua cidadania em sua forma mais plena, de alçada constitucional. [...] Não se pode olvidar que no exercício de sua mais ampla e irrestrita liberdade, $X$ tem direito de buscar melhor qualidade de vida por meio de satisfação de suas aspirações, e sua pretensão está representada, neste momento, pela alteração de seu prenome [...].

De fato, o que se verifica é que sua satisfação é sentir-se bem com a sua condição expressada por meio do seu nome e o que ele representa para si e para a coletividade, concretizando o seu direito à liberdade e à dignidade. É a identificação social e psicológica, conformação social entre o nome e a aparência, reconhecimento de sua condição de ser humano digno. Suas ações, modo de vida e opção pessoal não podem se constituir em meio de discriminação, mas, em realidade, são motivos que revelam sua verdadeira identidade. (grifos nossos)

Notemos a associação feita pelo relator entre decisão favorável e eliminação 
do sofrimento; o reconhecimento da cidadania e do acesso a direitos se dá a partir dessa eliminação e da viabilização de "melhor qualidade de vida" à requerente. Além da expectativa de narrativas de dor produzidas e qualificadas pela "doença", próprias de uma "pessoa transexual verdadeira", há uma lógica de reconhecimento da titularidade a direitos como parte de uma economia moral que enfrenta e repara a vulnerabilidade da requerente.

É como se a experiência de "adoecimento" requeresse como contrapartida formas de promoção ou recuperação de saúde que apenas poderiam se dar judicialmente - como se os tribunais exercessem um tipo de cuidado, nos termos de José Ricardo Ayres (2004, p. 22), que ultrapassa aspectos técnicos, alcança uma dimensão existencial e reivindica para si a responsabilidade de uma prática terapêutica que possa levar o indivíduo a retomar seus projetos de vida e de felicidade. A incompatibilidade entre identidade de gênero e documentos de identificação provocada pela doença causa sofrimento à pessoa transexual e julgadores(as) se veem no papel de corrigir esse descompasso e promover o bem-estar, a "normalidade" do(a) requerente em termos jurídicos. ${ }^{10}$

Isso se dá porque o sofrimento qualifica a pessoa transexual como vítima de uma patologia, da incoerência e dualidade que a doença suscita. E é esse lugar no qual os/as requerentes são inseridos(as) que os/as torna merecedores(as) de intervenção e proteção estatal. Como afirma Lucas Freire (2015, p. 128), a construção de pessoas transexuais enquanto sujeitos de direitos se dá a partir de sua produção enquanto indivíduos em situação de vulnerabilidade, enquanto vítimas, e pelo enfrentamento do principal fator que criou esse estado ao longo da vida da pessoa e ameaça seu futuro: a incompatibilidade que ameaçaria a identidade.

Cynthia Sarti (2009) demonstrou como a inserção na categoria de vítima se tornou meio de legitimação moral de indivíduos e como isso se relaciona com uma resposta positiva a suas demandas de reivindicação de direitos. Afirma a antropóloga que a forma como movimentos sociais de cunho identitário penetraram e ganharam espaço na seara jurídica marcou o modo como o Direito e a Saúde articulam violência, a construção prévia de uma figura legítima de vítima e o direito à atenção. Laura Moutinho também ressaltou como a abertura política, o processo de elaboração da Constituição de 1988 e os direitos nela inscritos "consolidar[am] de modo complexo o capital social e político da 'vítima' no interior de uma ampla economia moral que articula demandas sociais e identitárias” (2014, p. 214-215).

Mas, como ambas sugerem, "vítima” não se torna uma categoria universal na qual quaisquer indivíduos são inseridos: o processo de cristalização de identidades de determinados grupos sociais em cenários institucionais como o Direito e a Saúde faz com que recortes de gênero, raça, geração e classe se articulem na

${ }^{10}$ Para maior detalhamento da legitimação de decisões favoráveis como parte do processo terapêutico, ver Ventura e Schramm (2009). 
afirmação do merecimento dessa inserção - ao passo que a outros(as) é negado o reconhecimento de que possam sofrer violência ou de algum modo ser vitimados(as).

Por trás da criação de padrões de sujeito autorizados a ocupar o lugar de vítima e a ter acesso a direitos específicos há uma associação entre vitimização, merecimento e cidadania: não apenas pessoas específicas ("pessoas transexuais verdadeiras") e sofrimentos qualificados (causados pelo "transexualismo") são reconhecidos judicialmente; o reconhecimento da titularidade a direitos se dá porque, sendo pessoas específicas e tendo sofrimentos qualificados, são consideradas merecedoras de um rol determinado de direitos. A noção de cidadania não é universal ou garantida igualmente e nos mesmos termos a todos os indivíduos que nascem no país; direitos (bem como sua recusa, a possibilidade de sua violação e abuso) e obrigações são determinados a partir do reconhecimento da pessoa enquanto Pessoa e enquanto concretização de um modelo ("o transexual”) incluído em um sistema classificatório construído a partir da articulação de marcadores sociais da diferença.

José Murilo de Carvalho (2013[2001]) analisou o processo histórico de construção da cidadania no Brasil. Pensado enquanto titularidade a três grupos de direitos - direitos políticos, civis e sociais - o caminho de acesso à sua totalidade, bem como as dimensões que preponderam ao longo do tempo e entre grupos de indivíduos seriam muito peculiares e marcados por uma série de recortes sociais.

Investigando a lógica de conquista de direitos ao longo da história brasileira de 1822 ao governo FHC, o autor assevera que diferentemente do padrão de T.A. Marshall elaborado a partir do caso inglês, não tivemos primeiro o surgimento dos direitos civis, depois direitos políticos e então direitos sociais; Carvalho nos mostra como no Brasil a maior ênfase se deu inicialmente aos direitos sociais, implantados por Vargas em um cenário ditatorial de supressão de direitos políticos e repressão de direitos civis. Referindo-se a esse momento de consolidação de garantias de direitos nos anos 1930, o autor se vale do termo "cidadania regulada”, de Wanderley Guilherme dos Santos. Segundo este, trata-se de conceito

cujas raízes encontram-se não em código de valores políticos, mas em um sistema de estratificação ocupacional, e que, ademais, tal sistema de estratificação ocupacional é definido como norma legal. [...] são cidadãos todos aqueles membros da comunidade que se encontram localizados em qualquer uma das ocupações reconhecidas e definidas em leis. A extensão da cidadania se faz, pois, via regulamentação de novas profissões e/ou ocupações, em primeiro lugar, e mediante 
ampliação do escopo dos direitos associados a estas profissões, antes que por expansão dos valores inerentes ao conceito de membro da comunidade. A cidadania está embutida na profissão e os direitos do cidadão restringem-se aos direitos do lugar que ocupa no processo produtivo, tal como reconhecido por lei. (1979, p. 75)

Esse rol de direitos diferenciados conforme a profissão ocupada e seu reconhecimento estatal, afirma Carvalho, marcou o desenvolvimento da cidadania brasileira: quando da Constituinte de 1988, a organização de grupos específicos como forma de reivindicação e garantia de direitos específicos influenciou esse momento pós-ditadura de reestruturação de um corpo normativo próprio a um regime democrático e a um Estado de Direito. Declara: "os benefícios sociais não eram tratados como direito de todos, mas como fruto da negociação de cada categoria com o governo" (2013, p. 223).

Embora Carvalho se refira a categorias profissionais e ao corporativismo que teria influenciado a reelaboração do rol de direitos, gostaria de estender a lógica da cidadania regulada e da associação direta entre grupos de sujeitos e grupos de direitos ao modo como recortes de gênero, sexualidade, raça e classe produzem indivíduos cuja titularidade a certos direitos é reconhecida e a outros é negada. $\mathrm{O}$ caso de pessoas transexuais que requerem a retificação de nome e "sexo" em seus documentos é uma prova da produção estatal de atribuição diferenciada de direitos especiais.

A regulação não se dá apenas pelo meio legislativo. A produção discursiva de julgadores(as) marcada pelo esforço pedagógico em determinar o que é uma pessoa transexual leva a um modelo normativo. Quando transformam o encaixe perfeito de um indivíduo a essa categoria em condição de acesso a direitos determinados, como a retificação de registro, está-se diante de algo próximo à cidadania regulada de Santos.

Mauro Cabral e Paula Viturro, analisando um campo similar na Argentina, utilizam a noção de "cidadania (tran)sexual" para designar o conjunto de expectativas estabelecidas a pessoas transexuais como requisito ao reconhecimento legal de sua identidade de gênero e do acesso a direitos específicos, mas também para ressaltar que a produção de uma cidadania diferenciada implica, no contexto observado, a produção de desigualdades e de hierarquias de cidadãos(ãs):

By sexual citizenship, we refer to that which enunciates, facilitates, defends and promotes the effective access of citizens to the exercise of both sexual and reproductive rights and to a political subjectivity that has not been diminished by inequalities based on characteristics associated with sex, gender and reproductive capacity. [...] (Trans)sexual citizenship 
in Argentina may be identified as a diminished, decreased citizenship and that the natures of such diminution seriously compromises not only the citizen status of trans persons but also, centrally, their human status. (2006, p. 262, grifo dos(as) autores(as))

As categorias "cidadania (trans)sexual" e "cidadania regulada" permitem compreender não só o processo de produção de subjetividade política diferenciada de "pessoas transexuais verdadeiras" por meio de uma linguagem médico-científica e de diagnóstico positivo, qualificando-as como grupo particular de pessoas e direitos. Nota-se também a tessitura, prescritiva a partir de sua descrição, de pessoas legítimas, sofrimentos esperados e direitos diferenciados a serem concedidos em oposição a pessoas ilegítimas, sofrimentos invisibilizados e direitos negados a outras que não se encaixam no modelo.

Esse processo de validação de indivíduos e acesso a direitos controlados é apresentado como porta de entrada do pertencimento ao meio social "normal" - como se os requisitos, imperativos e limites à possibilidade de retificação de registro servissem como mecanismos de controle de sujeitos e de determinação dos que merecem ser inseridos no domínio de homens e mulheres "verdadeiros(as)”. A ação do Judiciário e a decisão favorável são representadas como parte conclusiva da prática terapêutica de pessoas transexuais, última etapa do processo de "correção" do descompasso vivido pela pessoa ao longo de sua vida - dessa vez, o reparo se dá na forma como a pessoa se relaciona em sociedade.

A doença é retratada como o motivo pelo qual o indivíduo sofre e não se relaciona bem consigo mesmo, mas também como a causa de sua marginalização e não participação do corpo social. O seu enfrentamento nas esferas da Saúde e do Direito é visto como fundamental para a resolução de conflitos nesses domínios de escalas distintas e para que, pessoa agora "normal" que se amoldou aos padrões sociais, ela possa ser um sujeito político da sociedade. Podemos ver no voto do relator na Ação de Apelação no 86.851-4/7, tramitada no Tribunal de Justiça de São Paulo e julgada em 21 de agosto de 2000:

Há uma dualidade dentro do próprio ser, que o impede de se bem relacionar e situar dentro da sociedade em que vive, dada a discriminação social existente, a ponto de se mutilar, sofrer, para não ser excluído. Note-se que entre um dos princípios que regem atualmente a Constituição Federal está a igualdade entre as pessoas. [...]. Como não reconhecer essa igualdade aos que querem participar do convívio social, submetendo-se à cirurgia de mudança de sexo, não para optar pelo gênero sexual masculino ou feminino, pois que não se trata de opção deliberadamente pensada, mas para 
encontrar sua própria personalidade, seu eu interior. Portanto, não se pode deixar de reconhecer ao autor o direito de viver como ser humano que é, amoldando-se à sociedade em que quer fazer parte. $\mathrm{E}$ não quer viver o autor como marginalizado, como discriminado, num estado de anomia e anomalia. Ele quer simplesmente merecer o respeito de sua individualidade, de ser um cidadão, um indivíduo comum. (grifos nossos)

O relator afirma que o enfrentamento em âmbito médico e jurídico do caráter marginalizador e desestabilizador da "doença" é a solução encontrada para que a requerente deixe de ocupar o exterior da norma e da normalidade. Essa transição se dá pela demonstração do diagnóstico positivo e da permanência da doença, pelo seu tratamento a partir da cirurgia de transgenitalização e pela conformidade a padrões de gênero e sexualidade articulados a moralidades, de modo que, no entendimento de magistrados(as), possam merecer a retificação de registro de modo a então serem homens e mulheres verdadeiros, legítimos, aceitáveis.

A busca dessa harmonia pela observância de normas sociais, e o não questionamento dessas próprias normas que conformam subjetividades e patologizam experiências, também pode ser notada na Ação de Apelação no 168.241-3, processada no Tribunal de Justiça do Paraná e julgada em 28 de junho de 2005. Ao Direito se atribui o dever de enfrentar o problema e reinserir a requerente à sociedade a partir da mudança do nome:

A situação de fato (realidade) apresentada pelo requerente não pode ser ignorada, pela ausência de legislação específica para a solução da questão, sob pena de mantê-lo esquecido e marginalizado, condenado a viver no submundo, obrigando-o a utilizar-se de documentos que o exponham a vexame e humilhação, em flagrante afronta ao exercício do direito fundamental de personalidade da pessoa humana. [...] É nos princípios que reside o aporte seguro para a solução da mudança do sexo jurídico e conseqüentemente do nome do requerente, porquanto sem a alteração será violado o seu direito à intimidade e a honra, em face do constrangimento a que está submetido, em cada oportunidade que se identifica. A busca da felicidade (emancipação) do requerente não pode ser impedida pelo direito, mantendo-o no estado de anomia e a anomalia, de forma a expressar o desprezo da realidade em flagrante discriminação. (grifo nosso)

Quando se leva em consideração tanto a exigência de se submeter a experi- 
ência transexual a um paradigma patologizante quanto a expectativa inserção de pessoas transexuais no rol de indivíduos "normais", "comuns", o efeito é contraditório e eloquente no que toca aos mecanismos de controle estatal de suas identidades de gênero e processos de subjetivação. Afirma Toby Beauchamp:

Thus two major forms of surveillance operate relative to trans people in the medical and psychiatric institutions. The first is the monitoring of individuals in terms of their ability to conform to a particular medicalized understanding of transgender identity and performance. But more salient to my argument is the second component, which is the notion that the primary purpose of medical transition is to rid oneself of any vestiges of non-normative gender: to withstand and evade any surveillance (whether visual, auditory, social, or legal) that would reveal one's trans status. To blend. To pass. Medical Science relies on standardized, normative gender presentation, monitoring trans individuals' ability to pass seamlessly as non-trans. Medical surveillance focuses first on individuals' legibility as transgender, and then, following medical interventions, on their ability to conceal any trans status or gender deviance. (2013, p. 47)

Isso pode ser aplicado ao Judiciário brasileiro. A cidadania transexual, para usar o termo de Cabral e Viturro, apresenta uma série de condições e limites aos indivíduos que pleiteiam sua aquisição porque é elaborada como porta de entrada ao mundo da "normalidade", da verdade, da legitimidade. É o que permite que a pessoa transexual seja vista como um indivíduo comum em suas relações econômicas, políticas, jurídicas, de afeto. Todo esse doloroso processo ao qual se submetem é um processo de retificação em todos os sentidos e não só em termos de correção de dados em documentos de identificação, porque corresponde a um intricado mecanismo de adequação a normas de gênero e à matriz heteronormativa apresentadas enquanto naturais, dados da realidade que organizam a sociedade e a subjetividade política. Primeiro os/as requerentes são lidos pela lógica do problema - afinal, a instabilidade e fluidez de seus corpos e gêneros precisam de uma explicação que não vulnerabilize as ditas matriz e normas -; depois, encontra-se uma solução. E, por fim, eliminada ou escondida qualquer forma de doença, podem ser reconhecidos enquanto normais, comuns.

\section{Considerações finais}


O campo judicial de disputa de cidadania transexual não se organiza em termos de inclusão de pessoas em um rol universal de direitos; neste artigo, pretendi demonstrar, com base em meu recorte etnográfico, que o processo decisório em ação nos tribunais brasileiros tem fundamento em uma dinâmica prévia de construção de um modelo de inteligibilidade a pessoas transexuais que não ameace a estabilidade da matriz cisheteronomartiva que organiza o ordenamento jurídico e o meio social. Essa matriz se apoia em sentidos de pessoa historicamente formados por ideias de unicidade, estabilidade, essência e autonomia individual. Experiências de transexualidade são apreendidas como incongruência e mistura patológicas de "sexos"; se o modelo de normalidade é o de pessoa estável e coerente - e isso inclui identidade sexuada -, à transexualidade "verdadeira" se associa um sofrimento esperado pela dita incongruência e à pessoa transexual "verdadeira" se associa um status de vítima da doença. Magistrados(as), junto a saberes e instituições biomédicas, tomam para si a tarefa de enfrentamento desse sofrimento e de "correção" de sujeitos, de modo a reinseri-los no meio social de normas e normalidade.

Mas a dinâmica judicial investigada também sugere um processo peculiar à história política brasileira de consolidação de cidadania fundada na relação direta entre grupos de sujeitos particulares e direitos particulares - nada mais comum, portanto, que se vincule a pessoas transexuais formas de proteção e acesso a serviços e garantias determinados. Ocorre que, ao articularmos esses dois processos, é possível notar que a constituição desse sistema classificatório não se dá com base apenas em fatores socialmente verificáveis na realidade, mas em expectativas normativas formadas pela associação entre saberes biomédicos, padrões de gênero e sexualidade (e outros marcadores sociais da diferença) e regimes de moralidade que homogeneízam e universalizam uma imagem de "identidade" transexual. Não se trata, portanto, de constatar o que a transexualidade é; desembargadores produzem o que a transexualidade deve ser, do que consideram uma pessoa transexual "verdadeira" ou "razoável". Esse mecanismo cria, inevitavelmente, grupos de pessoas consideradas legítimas, porque se enquadram nas expectativas e padrões elaborados, e que terão acesso a direitos, e grupos de pessoas ilegítimas - porque qualificadas como "falsas" ou "irrazoáveis" - a quem esses direitos serão negados.

\section{Referências bibliográficas}


ALMEIDA, Guilherme; MURTA, Daniela. Reflexões sobre a possibilidade da despatologização da transexualidade e a necessidade da assistência integral à saúde de transexuais no Brasil. Sexualidad, Salud y Sociedad - revista lationoamericana, Rio de Janeiro (IMS-UERJ, CLAM), n. 14, p. 380-407, 2013.

ARÁN, Márcia; MURTA, Daniela. Do diagnóstico de transtorno de identidade de gênero às redescrições da experiência da transexualidade: uma reflexão sobre gênero, tecnologia e saúde. Physis: revista de Saúde Coletiva, Rio de Janeiro (IMS-UERJ, CEPESC), v. 19, n. 1, p. 15-63, 2009.

AYRES, José Ricardo Carvalho de Mesquita. O cuidado, os modos de ser (do) humano e as práticas de saúde. Saúde e Sociedade, v. 13, n. 3, p. 16-29, set.-dez., 2004.

BEAUCHAMP, Toby. Artful Concealment and Strategic Visibility: transgender bodies and U.S. state surveillance after 9/11. In: STRYKER, S.; AIZURA, Z. A. (Eds.). The Transgender Studies Reader 2. Nova York/Londres: Routledge, 2013. p. 46-55.

BENTO, Berenice. A reinvenção do corpo: sexualidade e gênero na experiência transexual. Rio de Janeiro: Garamond, 2006.

BUTLER, Judith. Desdiagnosticando o gênero. Physis: revista de saúde coletiva, Rio de Janeiro (IMS-UERJ, CEPESC), v. 19, n. 1, p. 95-126, 2009.

Problemas de gênero: feminismo e subversão da identidade. 5.ed. Rio de Janeiro: Civilização Brasileira, 2013.

CABRAL, Mauro; VITURRO; Paula. (Trans)Sexual Citizenship in Contemporary Argentina. In: CURRAH, P.; JUANG, R. M.; MINTER, S. P. (Eds.). Transgender Rights. Minneapolis, London: University of Minnesota Press, 2006. p. 262-73.

CARVALHO, José Murilo de. Cidadania no Brasil: o longo caminho. 16.ed. Rio de Janeiro: Civilização Brasileira, 2013.

CARVALHO, Mario Felipe de Lima. A (im)possível pureza: medicalizações e militância na experiência de travestis e transexuais. Sexualidad, Salud y Sociedad - revista lationoamericana, Rio de Janeiro (IMS-UERJ, CLAM), n. 8, p. 36-62, 2011.

DUMONT, Louis. O individualismo: uma perspectiva antropológica da ideologia moderna. Rio de Janeiro: Rocco, 1985.

ENKE, A. Finn. The Education of Little Cis: cisgender and the discipline of opposing bodies. In: STRYKER, S.; AIZURA, Z. A. (Eds.). The Transgender Studies Reader 2. Nova York/Londres: Routledge, 2013. p. 234-47.

FREIRE, Lucas Magalhães. A máquina da cidadania: uma etnografia sobre a requalificação civil de pessoas transexuais. Dissertação (Mestrado) - Museu Nacional, Universidade Federal do Rio de Janeiro, Rio de Janeiro, 2015.

GLUCKMAN, Max. The Judicial Process Among the Barotse of Northern Rodhesia. Manchester: Manchester University Press, 1955. 
The Reasonable Man in Barotse Law. In: Order and Rebellion in Tribal Africa: collected essays with an autobiographical introduction. Londres: Routledge, 1963. p. 178-206.

LEITE JÚNIOR., Jorge. Nossos corpos também mudam: a invenção das categorias "travesti" e "transexual" no discurso científico. São Paulo: Annablume, Fapesp, 2011.

LIMA, Luiza Ferreira. A "verdade" produzida nos autos: uma análise de decisões judiciais sobre retificação de registro civil de pessoas transexuais em Tribunais brasileiros. Dissertação (Mestrado) - Faculdade de Filosofia, Letras e Ciências Humanas, Universidade de São Paulo, São Paulo, 2015.

MAUSS, Marcel. Uma categoria do espírito humano: a noção de pessoa, a de “eu”. In: Sociologia e antropologia. São Paulo: Cosac Naify, 2003. p. 367-97.

MOUTINHO, Laura. Diferenças e desigualdades negociadas: raça, sexualidade e gênero em produções acadêmicas recentes. Cadernos Pagu, n. 42, p. 201-248, jan.-jun., 2014.

OLIVEIRA, Rosa Maria Rodrigues de. Direitos sexuais de LGBT* no Brasil: jurisprudência, propostas legislativas e normatização federal. Brasília: Ministério da Justiça, Secretaria da Reforma do Judiciário, 2013.

PELUCIO, Larissa. Nos nervos, na carne, na pele: uma etnografia sobre prostituição travesti e o modelo preventivo de AIDS. Tese (Doutorado) - Centro de Educação e Ciências Humanas, Universidade Federal de São Carlos, São Carlos, 2007.

SANTOS, Wanderley Guilherme dos. Cidadania e justiça: a política social na ordem brasileira. Rio de Janeiro: Campos, 1979.

SARTI, Cynthia. Corpo, violência e saúde: a produção da vítima. Sexualidad, Salud y Sociedad - revista latinoamericana, Rio de Janeiro (IMS-UERJ, CLAM), n. 1, p. 89-103, 2009.

TEIXEIRA, Flavia do Bonsucesso. Dispositivos de dor: saberes-poderes que conformam as transexualidades. São Paulo: Annablume; Fapesp, 2013.

VENTURA, Miriam; SCHRAMM, Fermin Roland. Limites e possibilidades do exercício da autonomia nas práticas terapêuticas de modificação corporal e alteração da identidade sexual. Physis: revista de saúde coletiva, Rio de Janeiro, v. 19, n. 1, p. 65-92, 2009.

WARNER, Michael. Introduction: fear of a queer planet. Social Text, n. 29, p. 3-17, 1991.

É bacharel em Direito pela Universidade de São Paulo. Mestra e 
doutoranda em Antropologia Social pela mesma Universidade. Membro do Coletivo de Estudos de Corpo e Cidade (COCCIX/ NAU/USP) e do Núcleo de Estudos dos Marcadores Sociais da Diferença (NUMAS/USP). Atua principalmente nos seguintes temas de pesquisa: gênero, transexualidades, travestilidades e transgeneridades, discursos e políticas.

Recebido em 01/04/2016 Aceito para publicação 17/01/2017 